\title{
CORRECTION
}

\section{Correction to: The minimal clinically important difference for the nonarthritic hip score at 2-years following hip arthroscopy}

David A. Bloom ${ }^{1}$ (D) Daniel J. Kaplan ${ }^{1} \cdot$ David J. Kirby ${ }^{1} \cdot$ Daniel B. Buchalter ${ }^{1} \cdot$ Charles C. Lin $^{1} \cdot$ Jordan W. Fried $^{1}$. Nainisha Chintalapudi ${ }^{1} \cdot$ Thomas Youm $^{1}$

Published online: 3 February 2022

(C) The Author(s) under exclusive licence to European Society of Sports Traumatology, Knee Surgery, Arthroscopy (ESSKA) 2022

\section{Correction to:}

\section{Knee Surgery, Sports Traumatology, Arthroscopy} https://doi.org/10.1007/s00167-021-06756-9

The copyright holder for these articles were incorrectly given as 'The Author(s), under exclusive licence to The Author(s) under exclusive licence to European Society of Sports Traumatology, Knee Surgery, Arthroscopy (ESSKA)' but should have been 'The Author(s) under exclusive licence to European Society of Sports Traumatology, Knee Surgery, Arthroscopy (ESSKA)'.

The original article has been corrected.
Publisher's Note Springer Nature remains neutral with regard to jurisdictional claims in published maps and institutional affiliations.

The original article can be found online at https://doi.org/10.1007/ s00167-021-06756-9.

David A. Bloom

bloom.davida@gmail.com

1 NYU Langone Orthopedics, 333 East 38th Street, 4th Floor, New York, NY 10016, USA 